\title{
DIREITO FUNDAMENTAL À EDUCAÇÃO PÚBLICA DE QUALIDADE: EFETIVIDADE SEGUNDO OS PARÂMETROS DO CUSTO ALUNO QUALIDADE INICIAL
}

\author{
Maria da Graça Nobrega Bollmann ${ }^{1}$ \\ Franciele de Souza Caetano Vieira²
}

\section{RESUMO}

O direito à educação, embora esteja presente na legislação brasileira, ainda não está efetivamente aplicado. O presente artigo discute dimensões da qualidade da educação que sejam compreensíveis à população e exigíveis judicialmente. Analisa a legislação pertinente e com base em diferentes autores, aborda o direito fundamental à educação e o padrão de qualidade presente no Custo Aluno Qualidade inicial (CAQi). Discute o direito do acesso e da permanência de crianças, jovens e adultos à educação pública de qualidade assegurada pelo Estado. O CAQi pode preencher a lacuna legal para uma educação de qualidade e suprir os parâmetros mínimos para auferi-la.

Palavras-chave: Direito Fundamental à Educação; Qualidade de Ensino; Exigibilidade Jurídica.

\section{FUNDAMENTAL RIGHT TO PUBLIC EDUCATION QUALITY: EFFECTIVENESS ACCORDING TO THE PARAMETERS OF STUDENT COST INITIAL QUALITY}

\begin{abstract}
The right to education, despite being present in the Brazilian legislation, still suffers on being applied. This article deals with the dimensions of the education quality, which are at the same time understandable to the population and judicially enforceable. It analyzes the relevant legislation, and based on different authors, discusses the fundamental right to education and the pattern of the quality in Student Cost Initial Quality (CAQi) in Portuguese acronym). It also discusses the right of access and permanence of children, young and adults to public education of quality assured by the State. The CAQi can fill the legal gap to support for a quality education and meet the minimum parameters to concretize it.
\end{abstract}

KEYWORDS: Fundamental Right to Education; Teaching Quality; Legal enforceability.

\section{DERECHO FUNDAMENTAL A LA EDUCACIÓN PÚBLICA DE CALIDAD: EFECTIVIDAD SEGÚN LOS PARÁMETROS DEL COSTE ALUMNO CALIDAD INICIAL}

\section{RESUMEN}

\footnotetext{
${ }^{1}$ Doutorado em Educação pela Pontifícia Universidade Católica do Rio de Janeiro (1992) e Pós-Doutorado em Educação na Universidade de Lisboa (2009) como bolsista CAPES. Dedica-se à pesquisa e à docência na área da Educação com ênfase nos temas: Educação Superior; Política da Educação no Brasil e na América Latina; Educação e Movimentos Sociais; Financiamento da Educação; Formação de Professores e Trabalho Docente. Atua como docente do quadro permanente (tempo integral) da Universidade do Sul de Santa Catarina e exerceu o cargo de Coordenadora do Programa de Pós-Educação em Educação - mandatos 2007-2009, 20102013 e 2013-2016 (PPGE/Unisul). E-mail: <graçabol@uol.com.br>

${ }^{2}$ Mestre em Educação pela Universidade do Sul de Santa Catarina (PPGE/UNISUL) em 2016. Atualmente, é servidora técnico administrativa em educação da Universidade Federal de Santa Catarina - Campus Araranguá. É integrante do grupo de pesquisa sobre Remuneração de professores de escolas públicas da educação básica no contexto do FUNDEB e do PSPN. E-mail: <franciele.vieira@ufsc.br>
} 
El derecho a la educación, aunque esté presente en la legislación brasileña, todavía no está efectivamente aplicado. El presente artículo discute dimensiones de la calidad de la educación, que sean comprensibles a la población y exigibles judicialmente. Analiza la legislación pertinente, y basándose en diferentes autores, aborda el derecho fundamental a la educación y el parámetro de calidad presente en el Coste Alumno Calidad Inicial (CAQi) en su acrónimo en portugués). Discute el derecho del acceso y de la permanencia de niños, jóvenes y adultos a la educación pública de calidad garantizada por el Estado. El CAQi puede rellenar el hueco legal parana educación de calidad y suplir los parámetros mínimos para obtenerla.

Palabras-clave: Derecho Fundamental a la Educación; Calidad de Enseñanza; Exigibilidad Jurídica.

\section{Introdução}

Passadas mais de duas décadas desde a promulgação da Constituição da República Federativa do Brasil de 1988, ainda é possível afirmar que o debate em torno dos direitos fundamentais e de sua eficácia não perdeu no quesito atualidade, pelo contrário, lamentavelmente - em se considerando aqui justamente o problema da falta de efetividade - segue ocupando a pauta dos grandes desafios do Estado e da sociedade.

"O ensino será ministrado com a garantia de um padrão de qualidade". Com essas palavras a Constituição Federal de 1988 enuncia, em seu artigo 206, inciso VII, o compromisso do Estado em garantir não só a educação, mas educação de qualidade (BRASIL, 1988). Essa caução deve ser efetivada com uma oferta de educação escolar para todos, permeada por padrões e que seja capaz de atender aos diferentes interesses da maioria da população.

Assim, no constitucionalismo brasileiro, de forma amplamente inovadora, a Carta Magna de 1988 trouxe o princípio da dignidade da pessoa humana como o valor maior do Estado, o cerne constitucional supremo em torno do qual gravitam os demais direitos. Os direitos fundamentais, abarcando aí os direitos sociais são, pois, os guardiões desse princípio. Logo, a educação é um direito fundamental social, cujo cumprimento garante o gozo da dignidade humana.

O conceito atual de educação, que compõe a gama de direitos que asseguram a plenitude da dignidade humana, é elucidado por Dourado e Oliveira (2009, p. 203): 
A discussão acerca da qualidade da educação remete à definição do que se entende por educação. Para alguns, ela se restringe às diferentes etapas de escolarização que se apresentam de modo sistemático por meio do sistema escolar. Para outros, a educação deve ser entendida como espaço múltiplo, que compreende diferentes atores, espaços e dinâmicas formativas, efetivado por meio de processos sistemáticos e assistemáticos. Tal concepção vislumbra as possibilidades e os limites interpostos a essa prática e sua relação de subordinação aos macroprocessos sociais e políticos delineados pelas formas de sociabilidade vigentes. Nessa direção, a educação é entendida como elemento constitutivo e constituinte das relações sociais mais amplas, contribuindo, contraditoriamente, desse modo, para a transformação e a manutenção dessas relações.

No entanto, diversos fatores contribuem para o distanciamento da pretensão normativa da atual Constituição brasileira acerca dos direitos sociais e à transformação operada efetivamente na vida daqueles que se encontram sob o seu manto protetor. Entre tais fatores não se pode olvidar que, diante das profundas transformações sociais e econômicas do mundo atual, o conceito de qualidade na educação tem se tornado cada vez mais dinâmico e complexo na sua materialização.

Nessa concepção surge a necessidade de definir os parâmetros mínimos que possam garantir uma educação de qualidade conforme disposto em lei para, então, respaldar-se de subsídios a fim de pleitear uma ação positiva do Estado na efetivação do direito fundamental à educação com padrão de qualidade.

Em uma inversão da lógica que pauta o financiamento da educação e das demais políticas sociais no Brasil, o Custo Aluno Qualidade inicial (CAQi) surgiu a partir de um estudo realizado por um conjunto de especialistas de universidades brasileiras, institutos de pesquisa, professores, estudantes, ativistas e gestores educacionais que integram entidades vinculadas à Campanha Nacional pelo Direito à Educação. Composto por uma plêiade de elementos (custos de remuneração e formação de profissionais, materiais didáticos, estrutura do prédio e equipamentos, entre outros), "o CAQi determina quanto é preciso ser investido por aluno de cada etapa e modalidade da educação básica para que o país comece a oferecer um ensino com o mínimo de qualidade" (AÇÃO EDUCATIVA, 2010).

O Parecer CNE/CEB n 8/2010 (BRASIL, 2010) define normas para aplicação dos padrões mínimos de qualidade de ensino na Educação Básica, caracterizando-os como: (i) real valorização da carreira do magistério; (ii) ampliação do financiamento da educação; e 
(iii) melhoria na organização da gestão. Para dar conta desses desafios, os padrões mínimos de qualidade aparecem associados a um conjunto de insumos, expresso pelo Custo aluno Qualidade (CAQ) e pelo CAQi. Algumas dessas referências já constavam nos cadernos da Conferência Nacional de Educação (CONAE) e agora passam a integrar o Plano Nacional de Educação (PNE) 2014-2024, recentemente aprovado e sancionado pela Presidência da República, devendo, portanto, ser postas em prática.

Nesse sentido é o entendimento dos gestores da Campanha Nacional pelo Direito à Educação (2014), ao se referirem à importância da aprovação da implementação do CAQ e do CAQi, previstos no PNE 2014-2024 e elaborado na CONAE 2014.

O CAQi deve ser aprovado na Conae - Após a inclusão do CAQi (Custo Aluno-Qualidade Inicial) e do CAQ (Custo Aluno-Qualidade) na Lei 13.005/14, que institui o PNE (Plano Nacional de Educação), agora é a hora de lutar pela sua implementação. De acordo com o texto sancionado, o Brasil deve regulamentar e implementar o CAQi até 2016. Estima-se que a medida representará um aporte de mais de $\mathrm{R} \$ 37$ bilhões da União para a educação nos estados e municípios (CAMPANHA NACIONAL PELO DIREITO À EDUCAÇÃO, 2014).

Ainda, o Documento Referência da CONAE 2014, que ocorreu de 19 a 23 de novembro de 2014, em Brasília, esclarece a necessidade de efetivar o CAQi como modelo padrão de financiamento da Educação Básica pública no Brasil.

Considerando o desequilíbrio regional e a oferta de educação básica pública, o financiamento à educação deve tomar como referência o mecanismo do custo aluno-qualidade (CAQ), previsto no ordenamento jurídico brasileiro. O CAQ deve ser definido a partir do custo anual por aluno dos insumos educacionais necessários para que a educação básica pública adquira padrão de qualidade. A construção do CAQ exige amplo debate sobre o número de alunos por turma, remuneração adequada, formação inicial, continuada e condições de trabalho para os profissionais da educação, materiais necessários à aprendizagem dos estudantes (como salas de informática, biblioteca, salas de ciência etc.). Em suma, deve considerar o conjunto dos insumos necessários para a adequada relação de ensino-aprendizagem nas escolas públicas brasileiras que oferecem a educação básica. Como o CAQ representa o alcance de um padrão de qualidade próximo daquele verificado nos países mais desenvolvidos, é preciso que o Brasil universalize, ao menos, um padrão mínimo de 
qualidade. Nesse sentido, antes do CAQ é preciso consagrar o CAQi (custo aluno-qualidade inicial) (CONAE, 2014).

Para a aplicação efetiva de tais insumos que garantem o direito social à educação de qualidade, depende-se de prestações positivas do Estado. Todavia, se isto não for cumprido, é preciso ir além e encarar o direito à educação como direito fundamental social, passível de ser tutelado judicialmente, caso o Estado não promova a sua concretização.

A intenção de atribuir a determinado direito o status de fundamental não pode restringir-se à simples normativa descrita em papel. Ao contrário, é, acima de tudo, uma norma de caráter princípio lógico, dotada de força normativa, e cuja aplicação não se resume a casos pontuais e específicos, estando apta para promover eficácia dos valores garantidos pela Constituição Federal.

\section{Direito à educação}

O direito à educação está previsto no artigo 6ㅇ da Constituição Federal de 1988 como um direito fundamental de natureza social, sendo detalhado no Título VIII, Da Ordem Social, especialmente nos artigos 205 a 214, nos quais se encontra elencada uma série de aspectos que envolvem sua concretização. Entre eles estão os princípios e objetivos que o informam, os deveres de cada ente da Federação para com a garantia desse direito, a estrutura educacional brasileira, além da previsão de um sistema próprio de financiamento, que conta com a vinculação constitucional de receitas. Trata-se de parâmetros que devem pautar a atuação do legislador e do administrador público, bem como critérios que o Judiciário deve adotar quando chamado a julgar questões que envolvam a implementação desse direito (DUARTE, 2007).

A referida Constituição representou um avanço significativo em matéria educacional, estabelecendo, desde logo, a educação como um direito social fundante da cidadania e o primeiro na ordem das citações, ou seja, sem educação não há como contemplar uma cidadania ativa e participativa. A partir de então, estabelece o capítulo próprio da educação, onde retoma a questão da obrigatoriedade do ensino e a estabelece como direito público subjetivo, redundando, no dizer de Flach (2009, p. 511), na seguinte 
lógica: "[...] o sujeito deste direito é o indivíduo e o sujeito do dever é o Estado, sob cuja competência estiver esta etapa da escolaridade".

Ainda, em uma feliz síntese, esclarece Flach (2009, p. 513) que:

Embora a Constituição Brasileira possa estar eivada de contradições, se suas prescrições forem vivenciadas concretamente pela totalidade da sociedade, poderão ser desenvolvidos indicativos que contribuam para uma superação da realidade excludente, na qual a maioria da população se encontra.

Além da previsão constitucional, há uma série de outros documentos jurídicos que contêm dispositivos relevantes a respeito do direito à educação, tais como a Conferência de Jomtien, na Tailândia, em 1990; o Estatuto da Criança e do Adolescente (Lei no 8.069/90, BRASIL, 1990); Lei de Diretrizes e Bases da Educação Nacional (LDB) (Lei no 9.394/96, BRASIL, 1996); a Declaração Universal dos Direitos Humanos; Declaração das Nações Unidas para o Milênio (adotada em 2000, a qual afirma que, até 2015, todas as crianças deverão concluir o ensino primário, mas não faz referência à qualidade desse ensino), PNE (Lei no 13.005/2014), entre outros.

O direito à educação foi proclamado expressamente a partir da Declaração Universal dos Direitos Humanos em 1948 e, conforme demonstrado, e ainda que reafirmado em muitas ocasiões, seu conceito foi mudando com o passar dos anos.

Segundo Mello Filho (1986), o conceito de educação é mais compreensivo e abrangente que o da mera instrução. A educação objetiva propiciar a formação necessária ao desenvolvimento das aptidões, das potencialidades e da personalidade do educando. 0 processo educacional tem por meta qualificar o educando para o trabalho e prepará-lo para o exercício consciente da cidadania. O acesso à educação é uma das formas de realização concreta do ideal democrático.

O artigo 206, inciso VII da Carta Magna, diferentemente da maioria dos instrumentos internacionais, faz menção expressa à importância da qualidade da educação, tratando-a como um princípio basilar do ensino a ser ministrado, ou seja, garante o direito à educação com "padrão de qualidade" para todos (BRASIL, 1988). 
Nesse mesmo sentido, a LDB $\mathrm{n}-9.394 / 96$ foi promulgada sob a égide da Constituição Federal de 1988, e também menciona diretamente a questão da qualidade e a avaliação da educação em vários artigos. A "garantia de padrão de qualidade" é um dos onze princípios básicos para o ensino definidos no artigo $3^{\circ}$, bem como os artigos $4 ㅇ$, 8우 70,71 , 74 e 75 definem as principais diretrizes básicas que asseguram o "padrão mínimo de qualidade de ensino" (BRASIL, 1996).

Consoante à qualidade como aspecto inerente ao direito fundamental à educação, ressalta Monteiro (2003, p. 764, grifo do autor).

O direito à educação é um direito prioritário, mas não é direito a uma educação qualquer: é direito a uma educação com qualidade de 'direito do homem'.

[...]

Respeitar, proteger e realizar todos os direitos do ser humano, e o direito à educação em particular, são as principais obrigações de um Estado de Direito.

O direito à educação é um paradigma novo para repensar a educação, transfigurar a escola e recriar a identidade dos profissionais da educação.

Acrescenta, ainda, o autor:

Direito à educação não é direito apenas à disponibilidade e acessibilidade de uma educação qualquer, avaliada por indicadores meramente utilitários e quantitativos. É, por definição, direito a uma bem determinada qualidade de educação, a uma educação com qualidade ético-jurídica de direito do ser humano, isto é, cujas condições materiais, institucionais e pessoais respeitem todo o conteúdo normativo, devidamente interpretado, do direito à educação (MONTEIRO, 2003, p. 786 e 787).

Ou seja, o direito à educação, atualmente, abrange a garantia não só do acesso e da permanência, também a segurança do padrão de qualidade como um dos princípios segundo o qual se estruturará o ensino.

\section{Educação de qualidade}


Dito isto, compreende-se que muitas são as respostas que têm sido dadas à pergunta: o que é qualidade na educação? Algumas delas têm significação semelhante, outras variam em detalhes, inúmeras apresentam diferenças substanciais. Enunciado de várias formas, o conceito de qualidade na área educacional, de maneira geral, abarca as estruturas, os processos e os resultados educacionais.

Ao conjecturar sobre o tema qualidade, pode-se observar e assinalar que este é um tema complexo, tanto em relação à definição do conceito quanto à qualidade como prática.

Dourado, Oliveira e Santos (2007), Fonseca (2009), Nardi e Schneider (2012) demonstram que a superficialidade de diversas produções e múltiplos pontos de vista, nem sempre explícitos, contribuem para a imprecisão do conceito.

Por essa razão, é imprescindível munir-se, primeiramente, de subsídios que possibilitem a definição, ainda que de maneira mais geral, do conceito do termo qualidade, elucidando seu significado original e a forma como ele vem sendo empregado nas políticas educacionais.

Inicia-se pelos estudos de Bueno (1967, p. 3.276), que esclarece a qualidade como uma palavra proveniente do latim, cujo significado é "propriedade específica, própria de um ser vivo ou inanimado; aspecto determinado de uma realidade; maneira, modo, atributo, condição social".

Cury (2010) explica que, pela origem greco-latina, qualidade é um termo polissêmico, complexo e sem uniformidade característica, dificultando a sua compreensão, sua utilização em textos e na realidade humana concreta. O mesmo autor destaca a dimensão filosófica do conceito, expondo que, já em Aristóteles, a qualidade significa um modo de ser da coisa que os atinge neles mesmos ou que os acrescenta, supondo, assim, um sujeito e certa substância da qual fazem parte tanto quantidade como a qualidade; em outras palavras, uma grandeza mensurável e uma determinação que confere ou não ao modo do ser.

Da análise do pensamento marxista, compreende-se que quantidade e qualidade constituem a mesma realidade. Marx, em sua obra máxima, explicita a qualidade relacionada com a mercadoria e seu valor de uso, sendo a qualidade o que define a 
mercadoria. Além disso, distingue uma de outra no seu valor de uso e, consequentemente, do seu valor de troca (MARX, 1998). Afirma o autor: "a utilidade é então a mais importante e indispensável qualidade da mercadoria. A utilidade, que se realiza no uso ou no consumo, confere à mercadoria o seu valor de uso" (MARX, 1998, p. 13).

De acordo com esta perspectiva, na sociedade capitalista, os valores de uso se esvaem na mercadoria, pois se criam utilidades desnecessárias, fetichizando-as e tornando o ser humano escravo delas (MARX, 1998).

Na obra A Ideologia Alemã (MARX; ENGELS, 1979) é robustecida a ideia de qualidade e quantidade como componente uma da outra, em que uma transformação depende do desenvolvimento de ambas, que vão ocorrendo historicamente. Embora Marx não tenha se dedicado de maneira direta para a definição do significado de qualidade, foi Engels quem se aprofundou para dar sentido materialista às leis da dialética de Hegel e, por consequência, evidenciou com mais precisão a lei da passagem da quantidade para a qualidade.

Konder (1981), com referência em Engels, descreve que a modificação do todo só se realiza, de fato, após um acúmulo de mudanças nas partes que o compõem, com alterações setoriais quantitativas, até que se alcance um ponto crítico que marca a transformação qualitativa da totalidade. Ressalta que as coisas não mudam sempre no mesmo ritmo; o processo de transformação pelo qual elas existem passa por períodos lentos (nos quais se sucedem pequenas alterações quantitativas) e por períodos de aceleração (que precipitam alterações qualitativas, isto é, saltos, modificações radicais).

Cury também reafirma que "sucessivas mudanças [...] na quantidade [...] produziriam nele um salto de qualidade, propiciando-Ihe um outro [sic] modo de ser que subassume e supera o anterior" (CURY, 2010, p. 16).

Para Gramsci (2004, p. 164), “na filosofia da práxis, a qualidade está sempre ligada à quantidade; aliás, talvez resida nessa ligação a sua parte mais original e fecunda".

Por fim, em uma perspectiva materialista dialética, qualidade supõe quantidade e vice-versa, na qual um modo de ser é relativamente superior, enriquecido, representando um salto que diferencia e agrega o modo de ser primeiro. 
Apontado o significado conceitual do termo qualidade, torna-se indispensável, para apreendê-lo na sua totalidade, compreender que ele é produto da história. E, assim sendo, traz consigo significações que somente foram possíveis a partir de uma práxis, que foram se desenvolvendo gradativamente por contradições, até desempenhar a função ideológica dicotômica que traz a sociedade contemporânea.

Para tanto, na tentativa de refletir sobre a questão no contexto de elaboração de políticas públicas, destacam-se duas maneiras de arrazoar a qualidade: a óptica da qualidade total, que se vincula aos interesses capitalistas e ao (neo) liberalismo, tendo a escola como uma empresa, apresentando a lógica do capital como o melhor e único fim para a história da humanidade. Utiliza-se dessa instituição como ferramenta de conformação dos sujeitos à ordem para continuar a se reproduzir. A perspectiva da qualidade social joga nos interesses e necessidades da classe trabalhadora, em uma perspectiva democrática que compreende a escola como lócus de formação humana, aliando a apropriação do conhecimento científico à participação dos envolvidos nesse processo. Desta forma, propicia condições aos sujeitos para ter clareza sobre a realidade e seus determinantes, de modo a possibilitar ferramentas na busca de transformações que a sociedade exige.

Posicionando a discussão no campo da educação, pode-se afirmar que a qualidade não pode ser determinada da mesma maneira que o campo empresarial, isto porque os fins da escola não são os mesmos de uma empresa. Enquanto as empresas, na sociedade capitalista, são responsáveis pela produção de bens ou serviços para comercialização e extração de capital excedente, a escola tem a função de transmitir os conhecimentos sistematizados produzidos historicamente, além de formar sujeitos conscientes das relações sociais existentes, possibilitando compreender a sua totalidade, a fim de lutar contra as situações de injustiça nela presentes.

Brandalise (2002, p. 45) enfatiza que "não se trata, portanto, de produção de bens e serviços, mas de formação humana [...]",e que a qualidade de uma instituição escolar não pode ser medida como nas empresas: "somente pela eficiência e eficácia, ou seja, pela quantidade de alunos que atende, pelos recursos quantitativos e qualitativos que apresenta, pelos índices de desempenho dos alunos, pela presença de um bom diretor, embora eles sejam requisitos importantes" (BRANDALISE, 2002, p. 46). 
Mesmo que em sua origem não seja utilizada a expressão qualidade social em função de sua estrutura e características das propostas contidas no CAQi, resta evidente sua base democrática, fundada nas diretrizes da qualidade social.

A educação de qualidade social tem como pressupostos a educação como um direito de todos, radicalização da democracia e formação mais humana possível dos educandos (devido à restrição de possibilidades em uma sociedade capitalista). Além disso, podem-se salientar alguns eixos fundamentais e estruturantes dessa concepção educacional, que se relacionam e se completam: direito de cidadania, democratização da gestão democrática do acesso, democratização do conhecimento, financiamento e regime de colaboração e valorização dos trabalhadores em educação, e integração entre políticas e outros entes jurídicos.

Belloni (2003) aponta a qualidade social como direito de cidadania intimamente ligada a uma política de inclusão social, na qual a participação de todos os cidadãos é primordial para a construção de uma nova sociedade, mais justa e igualitária. Assinala, ainda, que a oferta de educação de qualidade como direito de cidadania contempla três dimensões específicas e complementares: acesso à educação, permanência no sistema ou em atividades educativas, e sucesso no resultado do aprendizado. Sendo educação de qualidade social "aquela comprometida com a formação do estudante com vistas à emancipação humana e social; tem por objetivo a formação de cidadãos capazes de construir uma sociedade fundada nos princípios da justiça social, da igualdade e da democracia" (BELLONI, 2003, p. 232).

Desse modo, o CAQi vem ao encontro dos anseios, a fim de definir um padrão de qualidade para todos, embasado em uma perspectiva democrática e de qualidade social, visando a uma escola de qualidade, não apenas para uma pequena elite de crianças e jovens, mas para o conjunto da população brasileira.

Custo Aluno Qualidade inicial (CAQi)

Postas tais premissas, passa-se a discutir como se dá o financiamento da educação na busca de uma melhor qualidade de ensino. 
No Brasil, ainda hoje, a lógica que permeia o financiamento da educação e, portanto, o gasto por aluno, é baseado na divisão entre os recursos da vinculação orçamentária e o número de alunos matriculados. Essa medida não tem sido capaz de garantir um padrão mínimo de qualidade, padrão este amplamente referido em diversos dispositivos legais.

Nesse sentido, o CAQi insere-se em uma nova forma de pensar o financiamento da educação, ao trazer como principal objetivo definir um padrão mínimo de gasto por aluno, capaz de ampliar o acesso das pessoas à escola.

A proposta do CAQi foi, inicialmente, elaborada pela Campanha Nacional pelo Direito à Educação e, hoje, é encampada pelo Conselho Nacional de Educação através do Parecer CNE/CEB no 8/2010, que teve como relator o conselheiro Mozart Neves Ramos, definindo o CAQi como referência para a construção da matriz de Padrões Mínimos de Qualidade para a Educação Básica Pública no Brasil. Partiu-se de um grande esforço para estabelecer o que seriam padrões mínimos de qualidade e qual o seu custo, tendo por referência a Constituição Federal, a LDB e o PNE (PINTO, 2012).

A fim de explicitar como se dá a definição do custo alun os idealizadores lançaram um livro na busca por construir uma trajetória capaz de colaborar na elaboração da matriz do CAQ, tendo ciência que esta definição é inicial e, por conseguinte, deve ser apenas o primeiro passo na caminhada da melhoria da qualidade educacional brasileira.

Nessa perspectiva, os integrantes da Campanha Nacional pelo Direito à Educação deixam claro que a qualidade preliminarmente definida no CAQi não é a qualidade ideal, mas o que denominam de qualidade inicial, uma vez que estabelece um ponto de partida, um padrão mínimo de qualidade que deve ser assegurado a todas as escolas do país, até porque os critérios de qualidade evoluem com o tempo. Isto é, o CAQi estabelece a definição de insumos essenciais ao desenvolvimento dos processos de ensino e aprendizagem que permitam uma educação pública de qualidade no Brasil - Índice de Desenvolvimento da Educação Básica (IDEB) igual a 6,0 pontos - como premissa básica para alcançar os padrões mínimos de qualidade das escolas públicas (PINTO, 2012).

Entre os avanços e retrocessos da legislação brasileira na definição de custo aluno-qualidade, tem-se a Constituição Federal como marco de garantia de um padrão 
mínimo de qualidade para todos. Contudo, até a aprovação do Fundo de Manutenção e Desenvolvimento da Educação Fundamental e Valorização do Magistério (FUNDEF) em 1996, não havia preocupação com padrão mínimo de qualidade, visto que o princípio que regulava o financiamento da educação era o dos recursos disponíveis por aluno, tendo por base os percentuais mínimos vinculados. Não havia a preocupação em se verificar se os valores assim disponibilizados garantiam um padrão mínimo de qualidade para o ensino oferecido. O FUNDEF determinou um prazo de cinco anos para o estabelecimento de recursos mínimos para o CAQ, definindo-o como princípio (CARREIRA; PINTO, 2007).

Um segundo passo importante para se atingir o CAQ foi a substituição do FUNDEF pelo Fundo de Manutenção e Desenvolvimento da Educação Básica e Valorização dos Profissionais da Educação (FUNDEB), criado pela Emenda Constitucional no 53/2006, regulamentado pela Lei no $11.494 / 2007$ e pelo Decreto no 6.253/2007, com vigência estabelecida para o período 2007-2020, que amplia os impostos vinculados, bem como as modalidades de atendimento, e estabelece a participação da comunidade na definição do CAQ. A partir disso, surgiu o conceito de CAQi, entendido como mais um passo rumo à educação pública de qualidade no Brasil (CARREIRA; PINTO, 2007).

José Marcelino Rezende Pinto, professor doutor em educação da Universidade de São Paulo (USP-Ribeirão Preto) e um dos elaboradores do CAQi, em resposta a uma entrevista sobre o valor da educação, explana com destreza o modelo de financiamento proposto pelo CAQi em relação aos outros tipos de financiamento da educação brasileira:

O sistema de financiamento educacional do Brasil parte do percentual determinado na Constituição: no mínimo $18 \%$ para a União e $25 \%$ para estados e municípios. Por mais que a lei fale que aquele é o piso, na prática torna-se o teto para os gastos. A pergunta é: isso garante a qualidade? Todos os estudos mostram que não. $O$ investimento por aluno no Brasil hoje está em torno de $\mathrm{R} \$ 150$, R\$ 200 por mês. É só comparar com qualquer escola privada para saber que é muito baixo. No CAQi, em vez de calcularmos quanto temos de recursos e dividir isso pelo número de alunos, calculamos qual seria o mínimo para dar qualidade ao ensino, não o ideal, mas o que garantisse um patamar mínimo, em que todas as escolas tivessem laboratório, biblioteca e uma quantidade razoável de alunos por turma, para dar condições ao professor de ensinar. O CAQi foi pensado a partir do que é necessário e quanto seria o custo para garanti-lo, mas é o mínimo, não a média (PINTO, 2014). 
Recentemente, o CAQi ganhou mais relevância com a aprovação do PNE, disposto na Lei no 13.005, de 25 de junho de 2014 (BRASIL, 2014), que contém, na meta de no 20, as estratégias 20.6; 20.7 e 20.10 , indicando um avanço considerável no que se refere ao alcance de um patamar mínimo de qualidade para a educação nacional, pois, se efetivadas, darão suporte para que o país se aproxime de padrões mínimos propostos pelos estudos acerca do CAQ. No conjunto do texto dessas três estratégias, respectivamente, encontram-se previstas: a implantação do CAQi no prazo de 2 (dois) anos da vigência do PNE com reajustes progressivos, a implementação do CAQ "[...] como parâmetro para o financiamento da educação de todas as etapas e modalidades da educação básica [...]" e, ainda, "[...] a complementação de recursos financeiros a todos os Estados, ao Distrito Federal e aos Municípios que não conseguirem atingir o valor do CAQi e, posteriormente, do CAQ" (BRASIL, 2014).

Dito isso, ressalta-se que a definição de dimensões, fatores e condições de qualidade trazidas pelo CAQi podem, além de definir insumos básicos para uma educação de qualidade, fazer avançar o controle social sobre a produção, implantação e monitoramento de políticas educacionais e seus resultados com relação à garantia do padrão da qualidade de ensino aprendizagem. Para isso, é preciso que tanto a comunidade escolar quanto a população disponham claramente das referências de qualidade descritas e discutidas, de forma a permitir o avanço na melhoria dos processos de formação e, portanto, no aproveitamento ou desempenho escolar dos alunos.

\section{Considerações finais}

À luz de todo o exposto, depreende-se que a educação pública de qualidade é um direito fundamental arrazoado na Constituição da República Federativa do Brasil de 1988 e, por isso, faz parte do patrimônio jurídico da cada cidadão brasileiro, além de, e principalmente, ser um dever objetivo do Estado.

Nesse passo, respalda-se na doutrina de Sarlet (2005), que conceitua direitos fundamentais, como educação e saúde, como normas de cunho constitucional expressas na 
Carta Magna vigente, com o objetivo de garantir direitos às pessoas contra abusos, desvios ou ilegalidades praticadas por aqueles que representam o Estado.

Para além dessa compreensão, dispõe a legislação brasileira que o direito à educação inclui os pais, o Estado, a comunidade em geral e os próprios educandos; porém, é obrigação do Estado garantir esse direito, inclusive quando o assunto é qualidade. Portanto, a qualidade da Educação Básica é um direito que requer uma ação positiva do Estado.

Sousa (2010) sabiamente ensina que o direito à educação é ainda mais latente quando se constata, na Carta de 1988, que foi elevado ao status de direito público subjetivo. Nesse contexto, o sentido de realização desse direito é forte a ponto de afastar qualquer recusa do Estado em efetivá-lo. E não basta só a garantia do direito à educação, fazem-se necessárias ações paralelas que permitam, à sociedade, as condições de chegar até à escola e manter-se nela, bem como a asseguração de sua qualidade pelo Estado.

Desse modo, conclui-se que o CAQi veio para suprir a lacuna da falta de respaldo legal do que efetivamente significa uma educação de qualidade e quais são os parâmetros mínimos iniciais para auferi-la. No entanto, tais padrões não são os desejados, pois significa o primeiro passo para chegar à qualidade ideal, por isso chama-se Custo Aluno Qualidade inicial.

Sendo assim, a qualidade da educação, ainda que compreendida como um conceito dinâmico, representa um compromisso com os sujeitos que participam do ambiente escolar, devendo ter sua implementação garantida pelo Estado. Tal direito deve ser requerido judicialmente através de ações judiciais que coercitivamente garantam atuação positiva do Estado em promover a qualidade da educação.

\section{Referências}

AÇÃO EDUCATIVA. Campanha Nacional pelo Direito à Educação. Sexta-feira, 22 de outubro de 2010. Disponível em: <http://www.acaoeducativa.org.br>. Acesso em: 25 out. 2015.

BELLONI, I. Educação. In: BITTAR, J. (Org.). Governos estaduais: desafios e avanços: reflexões e relatos de experiências petistas. São Paulo: Ed. Fundação Perseu Abramo, 2003. p. 30-100. 
BRANDALISE, M. A. T. A Cultura da qualidade no processo de gestão escolar: um desafio contemporâneo. 2002. 138 f. Dissertação (Mestrado em Educação)-Universidade Estadual de Ponta Grossa, Ponta Grossa, 2002.

BRASIL. Constituição (1988). Constituição da República Federativa do Brasil. Brasília, DF: Senado Federal, 1988. Disponível em:

<http://www.planalto.gov.br/ccivil 03/constituicao/constituicaocompilado.htm>. Acesso em: 30 ago. 2015.

Parecer CNE/CEB no 8, de 5 de maio de 2010. Estabelece normas para a aplicação do Inciso IX do artigo 40 da Lei no 9.394/96 (LDB), que trata dos padrões mínimos de qualidade de ensino para a educação básica pública. Disponível em: <http://portal.mec.gov.br/>. Acesso em: 10 nov. 2015.

. Lei no 9.394/96, de 20 de dezembro de 1996. Lei de Diretrizes e Bases da Educação Nacional. Disponível em: <http://www.planalto.gov.br/ccivil 03/leis/19394.htm>. Acesso em: 30 ago. 2015.

. Lei no 13.005, de 25 de junho de 2014. Aprova o Plano Nacional de Educação (PNE) e dá outras providências. Diário Oficial da União [da] República Federativa do Brasil. Brasília, 26 jun. 2014. Disponível em: <http://www.planalto.gov.br/ccivil 03/ Ato20112014/2014/Lei/L13005.htm>. Acesso em: 20 nov. 2015.

BUENO. F. S. Grande dicionário etimológico-prosódico da língua portuguesa. São Paulo: Saraiva, 1967. v. 7.

CAMPANHA NACIONAL PELO DIREITO À EDUCAÇÃO. Campanha conta com quase 100 delegados para defender a Lei do SNE e o CAQi na CONAE 2014. Fórum Nacional de Educação. 18 de novembro de 2014. Disponível em: <http://www.campanhaeducacao.org.br/?idn=1396>. Acesso em: 25 nov. 2015.

CARREIRA, D.; PINTO, J. M. R. Custo Aluno-Qualidade Inicial: rumo à educação pública de qualidade no Brasil. São Paulo: Global: Campanha Nacional pelo Direito à Educação, 2007.

CONAE. 2014. Documento Referência. Disponível em:

<http://fne.mec.gov.br/images/pdf/documentoreferenciaconae2014versaofinal.pdf>. Acesso em: 25 nov. 2015.

CURY, C. R. J. Qualidade em Educação. Nuances: estudos sobre Educação. p. 15-31, jan./dez. 2010. Disponível em: $<$ http://revista.fct.unesp.br/index.php/Nuances/article/view/721 >. Acesso em: 08 out. 2015.

DOURADO, L. F.; OLIVEIRA, J. F. A qualidade da educação: perspectivas e desafios. Cad. CEDES, v. 29, n. 78, 2009. 
DOURADO, L. F.; OLIVEIRA, J. F.; SANTOS, C. A. Políticas e gestão da educação básica no Brasil: limites e perspectivas. Educação \& Sociedade, Campinas, v. 28, n. 100, 2007.

DUARTE, C. S. A educação como um direito fundamental de natureza social. Scielo. 2007. Disponível em: <http://www.scielo.br/pdf/es/v28n100/a0428100>. Acesso em: 15 ago. 2015.

FLACH, S. F. O direito à educação e sua relação com a ampliação da escolaridade obrigatória no Brasil. Ensaio: Avaliação e Políticas Públicas, Rio de Janeiro, v. 17, n. 64, p. 495-520, jul./set. 2009.

FONSECA, M. Políticas Públicas para a qualidade da educação brasileira: entre o utilitarismo econômico e a responsabilidade social. Cadernos CEDES, Campinas, v. 29, n. 78, p. 153-177, 2009.

GRAMSCI, A. Cadernos do cárcere. Introdução ao estudo da filosofia. A filosofia de Benedetto Croce. Tradução de Carlos Nelson Coutinho. 3. ed. Rio de Janeiro: Civilização Brasileira, 2004. v. 1.

KONDER, L. O que é dialética. São Paulo: Editora Brasiliense, 1981.

MARX, K. O capital: crítica da economia política. Livro 1. São Paulo: Boitempo, 1998.

MARX, K.; ENGELS, F. A Ideologia Alemã. Tradução de José Carlos bruni e Marco Aurélio Nogueira São Paulo: Editora Ciências Humanas Ltda, 1979.

MELLO FILHO, José Celso de. Constituição Federal Anotada. 2. ed. São Paulo: Saraiva, 1986.

MONTEIRO, A. R. $O$ pão do direito à educação. Scielo. 2003. Disponível em: <http://www.scielo.br/pdf/es/v24n84/a03v2484>. Acesso em: 25 nov. 2015.

NARDI, E. L.; SCHNEIDER, M. P. Qualidade (social) na educação básica: o desafio da construção nos municípios do oeste catarinense. In: IX ANPED SUL, 2012. Anais eletrônicos... Disponível em:

<http://www.ucs.br/etc/conferencias/index.php/anpedsul/9anpedsul/paper/viewFile/807/9 9. . Acesso em: 10 set. 2015.

PINTO, J. M. R. Custo Aluno-Qualidade Inicial (CAQi). Trabalho docente na educação básica no Brasil. 2012. Disponível em: <http://trabalhodocente.net.br/?pg=dicionarioverbetes\&id=111>. Acesso em: 19 nov. 2015. 
. O valor da educação. Revista Escola Pública, 41. ed., jul. 2014. Disponível em: <http://revistaescolapublica.uol.com.br/textos/25/o-valor-da-educacao-255576-1.asp>. Acesso em: 19 nov. 2015.

SARLET, I. W. A Eficácia dos direitos fundamentais. 5. ed. Porto Alegre: Livraria do Advogado, 200

SOUSA, E. F. Direito à educação: requisito para o desenvolvimento do país. São Paulo: Saraiva, 2010.

BRASIL, USP . Declaração Universal dos Direitos Humanos (1948). Disponível em: < http://www.dudh.org.br/declaracao/>. Acesso em 30 de set. 2015.

MENEZES, Ebenezer Takuno de; SANTOS, Thais Helena dos. Verbete Conferência de Jomtien. Dicionário Interativo da Educação Brasileira - Educabrasil. São Paulo: Midiamix, 2001. Disponível em: <http://www.educabrasil.com.br/conferencia-de-jomtien/>. Acesso em: 15 de set. 2015.

BRASIL. Lei no 8.069 de 13 de julho de 1990. Estatuto da Criança e do Adolescente <www.planalto.gov.br/ccivil 03/leis/L8069Compilado.htm> Acesso em: 17 de set. 2015.

Nações Unidas. Declaração do Milénio das Nações Unidas (2000) - Unric <https://www.unric.org/html/portuguese/uninfo/DecdoMil.pdf> Acesso em 15 de set. 2015.

RECEBIDO EM 10 DE OUTUBRO DE 2016.

APROVADO EM 31 DE OUTUBRO DE 2016. 